\title{
Thermal Stability and Magnetic Properties of Fe-Nd-Al Amorphous Alloys
}

\author{
Ding Chen*, Akira Takeuchi and Akihisa Inoue \\ Institute for Materials Research, Tohoku University, Sendai 980-8577, Japan
}

\begin{abstract}
Iron-rich $\mathrm{Fe}_{50} \mathrm{Nd}_{50-x} \mathrm{Al}_{x}(x=5,10,15,20$ at\%) alloys were produced by copper mold casting and melt-spinning in order to examine the formation of amorphous alloys. The bulk amorphous cylinders with diameters up to $1.5 \mathrm{~mm}$ have been obtained for the $\mathrm{Fe}_{50} \mathrm{Nd}_{35} \mathrm{Al}_{15}$ alloy. The crystallization temperature $\left(T_{\mathrm{x}}\right)$ and melting temperature $\left(T_{\mathrm{m}}\right)$ of the alloy are 774 and $880 \mathrm{~K}$, respectively. Accordingly, the temperature interval of $T_{\mathrm{m}}$ and $T_{\mathrm{x}}, \Delta T_{\mathrm{m}}\left(=T_{\mathrm{m}}-T_{\mathrm{x}}\right)$, is calculated to be $106 \mathrm{~K}$, and the reduced crystallization temperature $\left(T_{\mathrm{x}} / T_{\mathrm{m}}\right)$ is 0.88 . The small $\Delta T_{\mathrm{m}}$ and high $T_{\mathrm{x}} / T_{\mathrm{m}}$ values are presumed to be the origin for the achievement of the high amorphous-forming ability of the Fe-Nd-Al alloy. The bulk amorphous cylinder exhibits semi-hard magnetic properties at room temperature, i.e., $0.117 \mathrm{~T}$ for remanence and $50 \mathrm{kA} / \mathrm{m}$ for intrinsic coercive field for $\mathrm{Fe}_{50} \mathrm{Nd}_{35} \mathrm{Al}_{15}$ alloy with a diameter of $1.5 \mathrm{~mm}$. Moreover, soft to hard magnetic transition between the ribbon and bulk specimens was observed in the Fe-rich Fe-Nd-Al alloys. The semi-hard magnetic properties for the Fe-rich Fe-Nd-Al amorphous alloys with high amorphousforming ability are promising for future progress as a new type of Fe-based magnetic material.
\end{abstract}

(Received May 24, 2005; Accepted July 15, 2005; Published December 15, 2005)

Keywords: bulk amorphous alloy, iron-neodymium-aluminum alloy, amorphous-forming ability, reduced crystallization temperature, semihard magnetic properties

\section{Introduction}

Since the first success in fabricating a bulk metallic glass in $\mathrm{La}-\mathrm{Al}-\mathrm{Cu}$ systems in $1989,{ }^{1)}$ a number of bulk metallic glasses with sizes greater than a couple of millimeters have been sequentially developed in $\mathrm{Ln}-\mathrm{Al}-\mathrm{TM},{ }^{1,2)} \mathrm{Mg}-\mathrm{Ln}-$ $\mathrm{TM}^{3,4)} \mathrm{Zr}-\mathrm{Al}-\mathrm{TM},{ }^{5,6)} \mathrm{Ti}-\mathrm{Zr}-\mathrm{Al}-\mathrm{TM}-\mathrm{Be},{ }^{7)} \mathrm{Zr}-\mathrm{Ti}-\mathrm{TM}-\mathrm{Be}^{8)}$ and $\mathrm{Pd}-\mathrm{Ni}-\mathrm{Cu}-\mathrm{P}^{9)}(\mathrm{Ln}=$ lanthanide metal, $\mathrm{TM}=$ transition metal) systems. These bulk metallic glasses have attracted scientific and engineering interests in the field of material science because of their high possibility to be formed as application products with novel functions. For instance, rather good mechanical properties and high thermal properties were reported for the bulk metallic glasses in nonferrous alloy systems mentioned aboved. ${ }^{1-9)}$ In addition, bulk metallic glasses were also found in a number of ferrous systems such as $\mathrm{Fe}-(\mathrm{Al}, \mathrm{Ga})-(\mathrm{P}, \mathrm{C}, \mathrm{B}, \mathrm{Si}, \mathrm{Ge})$ system with soft ferromagnetism. ${ }^{10-13)}$ Beside the ferrous and nonferrous bulk metallic glasses listed above, it was reported that $\mathrm{Nd}-\mathrm{Fe}-\mathrm{Al}$ amorphous alloys were formed in a bulk shape with the maximum sample of $12 \mathrm{~mm},{ }^{14)}$ and that the $\mathrm{Nd}-\mathrm{Fe}-\mathrm{Al}$ bulk amorphous alloys exhibited hard magnetism. ${ }^{15)}$ Here, these $\mathrm{Nd}-\mathrm{Fe}-\mathrm{Al}$ alloys are called as amorphous alloys because they did not exhibit glass transition in thermal analyses. The $\mathrm{Nd}-\mathrm{Fe}-\mathrm{Al}$ bulk amorphous alloys have been widely investigated $^{16-19)}$ because of their excellent amorphous-forming ability and unique hard-magnetic properties. For instance, the effects of $\mathrm{B}$ on the formation and the hard-magnetic properties were studied by Kong et al. ${ }^{20)}$ Takeuchi and Inoue $^{21)}$ and Chau et al. ${ }^{22)}$ The thermal stability and magnetic properties of $\mathrm{Nd}-\mathrm{Fe}-\mathrm{Co}-\mathrm{Al}$ amorphous alloys were studied by Fan et $a l .{ }^{23)}$ Kumar et $a l .{ }^{24)}$ and Wei et al. ${ }^{25)}$ In addition, the effect of Y was studied by Qiu et al. ${ }^{26)}$ and Sun et al. ${ }^{27)}$ and that of Si by Chiriac and Lupu, ${ }^{28)}$ and those of $\mathrm{Ti}$ and $\mathrm{V}$ by Chau et al. ${ }^{29)}$ In spite of great endeavors for improving the properties of the $\mathrm{Nd}-\mathrm{Fe}-\mathrm{Al}$ alloys, the magnetization of these Nd-rich amorphous alloys is as small as $0.1-0.3 \mathrm{~T}$ because of

*Graduate Student, Tohoku University the low Fe content ranging 60-70 at\%. Accordingly, it is of great importance to develop bulk amorphous $\mathrm{Nd}-\mathrm{Fe}-\mathrm{Al}$ alloys with higher Fe contents for respect to improving the magnetization of the alloys with keeping the high amorphous-forming ability. The purpose of the present study is to examine the formation of bulk amorphous alloys in Fe-rich $\mathrm{Fe}-\mathrm{Nd}-\mathrm{Al}$ system with the Fe content more than 50 at $\%$ by the conventional copper mold casting method, and to investigate the thermal stability and magnetic properties of these bulk amorphous alloys.

\section{Experimental}

Ternary alloys with compositions of $\mathrm{Fe}_{50} \mathrm{Nd}_{50-x} \mathrm{Al}_{x}$ $(x=5,10,15,20$ at $\%)$ were prepared by induction-melting a mixture of pure $\mathrm{Nd}, \mathrm{Fe}$ and $\mathrm{Al}$ metals in an argon atmosphere. These alloy compositions was selected according to previous reports on the composition range in which an amorphous phase is formed in the $\mathrm{Nd}-\mathrm{Fe}-\mathrm{Al}$ ternary system by melt spinning. ${ }^{15)}$ From these pre-alloyed ingots cylindrical samples with a length of about $50 \mathrm{~mm}$ and with diameters ranging 1 to $2 \mathrm{~mm}$ were prepared by injection casting of the molten alloy into copper molds with cylindrical cavities. The injection pressure was fixed to be $0.05 \mathrm{MPa}$. For comparison, amorphous ribbons with a thickness of about 30-40 $\mu \mathrm{m}$ and a width of $1 \mathrm{~mm}$ were also produced by a single-roller melt spinning method in an argon atmosphere. The structure of the as-cast cylindrical samples was examined by X-ray diffractometry and optical microscopy techniques. The thermal stability associated with crystallization and melting was measured at a heating rate of $0.67 \mathrm{~K} / \mathrm{s}$ by differential scanning calorimetry (DSC). Magnetic properties were measured with a vibrating sample magnetometer (VSM) under an applied field of $1432 \mathrm{kA} / \mathrm{m}$ at room temperature.

\section{Results and Discussion}

Figure 1 shows the $\mathrm{X}$-ray diffraction patterns taken from a transverse cross section of the $\mathrm{Fe}_{50} \mathrm{Nd}_{50-x} \mathrm{Al}_{x}$ alloys with a 


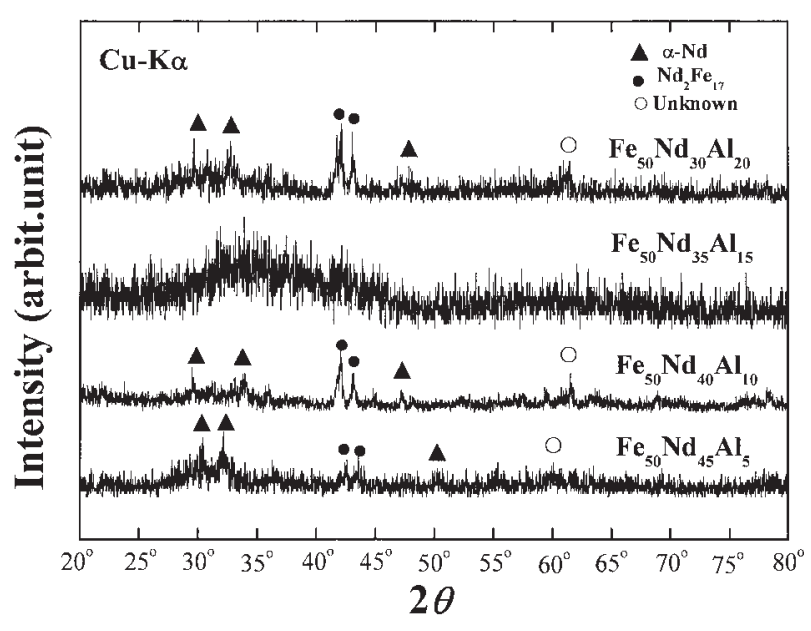

Fig. 1 The X-ray diffraction patterns of the $\mathrm{Fe}_{50} \mathrm{Nd}_{50-x} \mathrm{Al}_{x}(x=5,10,15$, 20) bulk alloys with a diameter of $1.0 \mathrm{~mm}$.

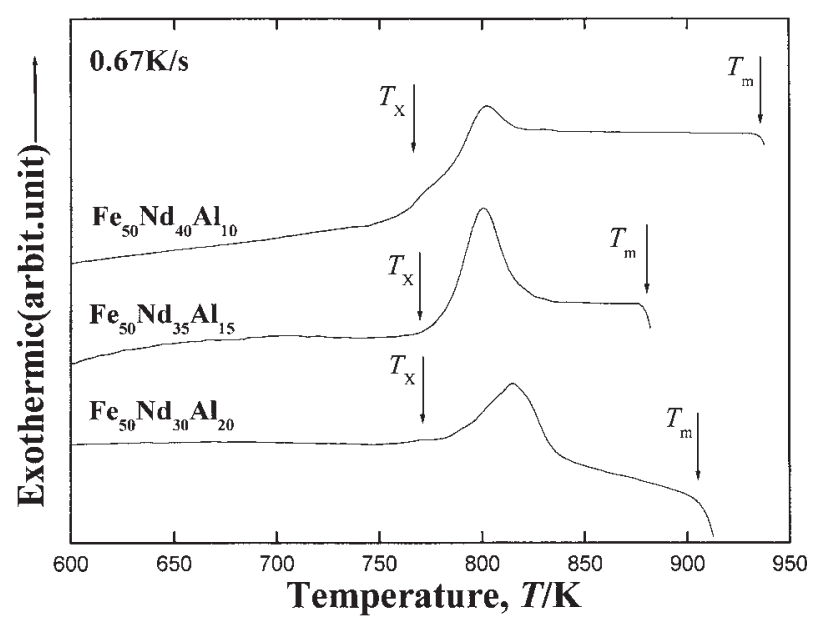

Fig. 2 The DSC curves of the melt-spun $\mathrm{Fe}_{50} \mathrm{Nd}_{50-x} \mathrm{Al}_{x}(x=10,15,20)$ amorphous alloys.

diameter of $1 \mathrm{~mm}$. The $\mathrm{Fe}_{50} \mathrm{Nd}_{35} \mathrm{Al}_{15}$ alloy exhibits a halo pattern while the other alloys exhibit sharp peaks which can be interpreted as reflections from the crystalline phases consisting of $\alpha-\mathrm{Nd}, \mathrm{Nd}_{2} \mathrm{Fe}_{17}$ and unknown phases. Thus, it can be said that only the $\mathrm{Fe}_{50} \mathrm{Nd}_{35} \mathrm{Al}_{15}$ alloy has the high amorphous-forming ability to be fabricated in a bulk form in the $\mathrm{Fe}_{50} \mathrm{Nd}_{50-x} \mathrm{Al}_{x}(x=5,10,15,20)$ systems.

From the Fig. 1, it is noticed that there are different in the best amorphous forming ability compositions of $\mathrm{Al}$ between the $\mathrm{Fe}-\mathrm{Nd}-\mathrm{Al}$ and $\mathrm{Nd}-\mathrm{Fe}-\mathrm{Al}$ bulk amorphous alloys. The former is $15 \%$ and the latter is $10 \%$. The reason for $\mathrm{Fe}-\mathrm{Nd}-$ $\mathrm{Al}$ alloys exhibiting the best amorphous forming ability at $\mathrm{Al}=15$ at $\%$ is ascribed with $T_{\mathrm{x}} / T_{\mathrm{m}}$ for the melt-spun $\mathrm{Fe}_{50} \mathrm{Nd}_{50-x} \mathrm{Al}_{x}(x=10,15,20)$ amorphous alloys. Figure 2 show the DSC curve of the melt-spun $\mathrm{Fe}_{50} \mathrm{Nd}_{50-x} \mathrm{Al}_{x}$ $(x=10,15,20)$ amorphous alloys. From DSC measurements, it is analyzed that the $T_{\mathrm{m}}$ is the lowest at $X=15$ at $\%$ while the $T_{\mathrm{x}}$ 's are almost unchanged. Accordingly, the value of $T_{\mathrm{x}} / T_{\mathrm{m}}$ is maximum when the content of $\mathrm{Al}$ is equal to 15 at $\%$. This analysis is supports the experimental results shown in Fig. 1, because the $T_{\mathrm{x}} / T_{\mathrm{m}}$ can be an index for evaluating the amorphous forming ability.

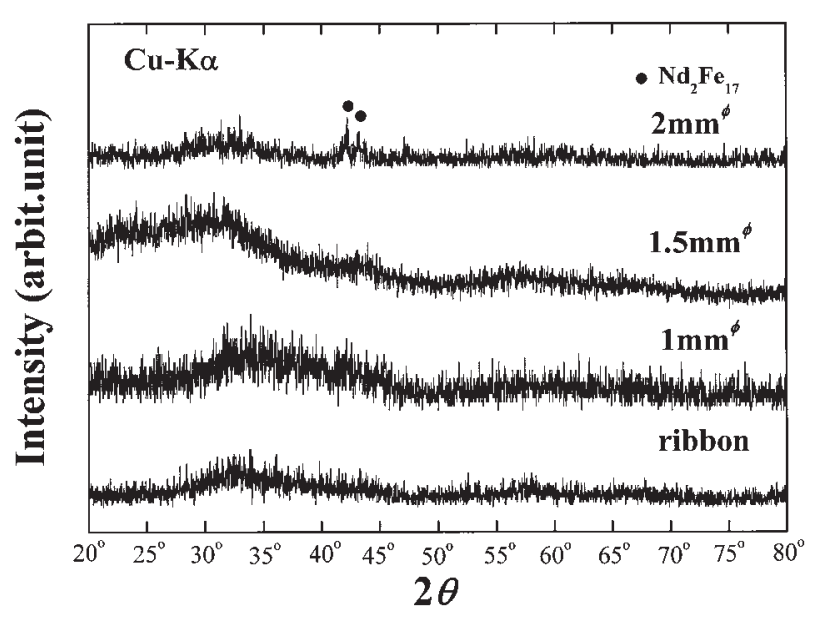

Fig. 3 The $\mathrm{X}$-ray diffraction of the $\mathrm{Fe}_{50} \mathrm{Nd}_{35} \mathrm{Al}_{15}$ cylinder with diameter of $1,1.5$ and $2 \mathrm{~mm}$. The data of the melt-spun ribbon are shown for comparison.

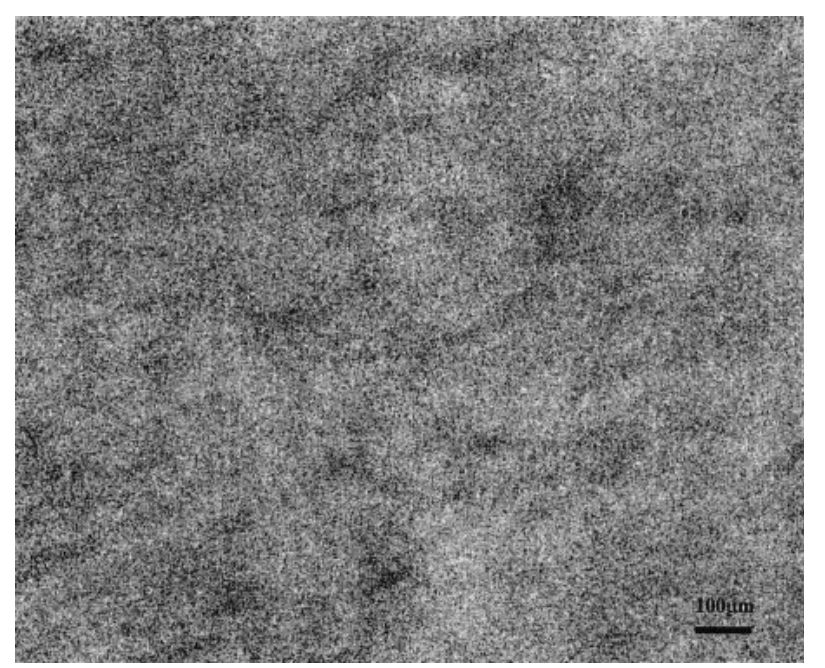

Fig. 4 The optical micrograph of the central region in the cast $\mathrm{Fe}_{50} \mathrm{Nd}_{35} \mathrm{Al}_{15}$ cylinder with a diameter of $1.5 \mathrm{~mm}$.

Figure 3 shows the $\mathrm{X}$-ray diffraction patterns taken from a transverse cross section of the $\mathrm{Fe}_{50} \mathrm{Nd}_{35} \mathrm{Al}_{15}$ alloys with different sample sizes, together with data of the melt-spun amorphous ribbon for comparison. The diffraction patterns of $\mathrm{Fe}_{50} \mathrm{Nd}_{35} \mathrm{Al}_{15}$ alloys with diameters of 1 and $1.5 \mathrm{~mm}$ consist only of halo patterns with the highest intensity at the wave vector $\left(K_{\mathrm{p}}=2 \pi \sin \theta / \lambda\right)$ of about $22.1 \mathrm{~nm}^{-1}$, indicating that an amorphous phase is formed in these bulk samples. On the contrary, sharp peaks corresponding to the reflection of $\mathrm{Nd}_{2} \mathrm{Fe}_{17}$ phase can be seen for the sample with a diameter of $2 \mathrm{~mm}$. Thus, the maximum diameter of the $\mathrm{Fe}_{50} \mathrm{Nd}_{35} \mathrm{Al}_{15}$ amorphous alloy is $1.5 \mathrm{~mm}$. In order to confirm the absence of the crystalline phase over the whole sample, an optical micrograph taken from the central region in the cast $\mathrm{Fe}_{50} \mathrm{Nd}_{35} \mathrm{Al}_{15}$ alloy with a diameter of $1.5 \mathrm{~mm}$ is shown in Fig. 4. Featureless contrast which is typical for an amorphous phase is seen over the whole micrograph, indicating that the bulk alloy is mainly composed of an amorphous phase. Furthermore one can notice the absence of cavity and hole which are ordinarily observed for cast samples. 


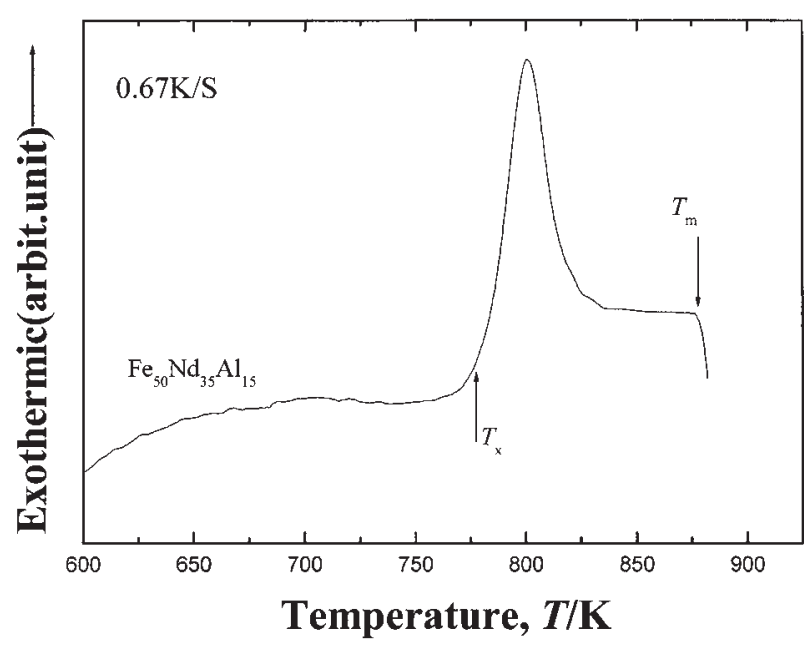

Fig. 5 The DSC curve of the as-cast $\mathrm{Fe}_{50} \mathrm{Nd}_{35} \mathrm{Al}_{15}$ cylinder with the diameter of $1.5 \mathrm{~mm}$.

Figure 5 shows the DSC curve of the $\mathrm{Fe}_{50} \mathrm{Nd}_{35} \mathrm{Al}_{15}$ bulk amorphous alloy. The fragments of for the measurement were taken from the same central region of the specimen shown in Fig. 4. The DSC curve of this alloy shows a distinct exothermic reaction due to crystallization marked with $T_{\mathrm{x}}$, followed by an endothermic reaction due to melting marked with $T_{\mathrm{m}}$ which are measured to be 774 and $880 \mathrm{~K}$, respectively. Furthermore, as exemplified for the alloys in Fig. 5, the temperature interval of supercooled liquid defined by the difference between $T_{\mathrm{x}}$ and $T_{\mathrm{m}}, \Delta T_{\mathrm{m}}\left(=T_{\mathrm{m}}-T_{\mathrm{x}}\right)$, is as small as $106 \mathrm{~K}$ and the reduced crystallization temperature $\left(T_{\mathrm{x}} / T_{\mathrm{m}}\right)$ is as high as 0.88 . Since no glass transition phenomenon is observed in the temperature range below crystallization temperature, the glass transition temperature $\left(T_{\mathrm{g}}\right)$ is estimated to be higher than $T_{\mathrm{x}}$. Consequently, the $T_{\mathrm{x}} / T_{\mathrm{m}}$ seems to correspond to the lowest reduced glass transition temperature $\left(T_{\mathrm{g}} / T_{\mathrm{m}}\right)$ for this alloy. The high amorphous-forming ability for the present $\mathrm{Fe}_{50} \mathrm{Nd}_{35} \mathrm{Al}_{15}$ alloy is, thus, concluded to result from the small $\Delta T_{\mathrm{m}}$ and high $T_{\mathrm{x}} / T_{\mathrm{m}}$ values. The extremely high $T_{\mathrm{x}} / T_{\mathrm{m}}$ value and the small $\Delta T_{\mathrm{m}}$ imply a steep increase in viscosity with the decreasing temperature in the supercooled liquid of the $\mathrm{Fe}-$ $\mathrm{Nd}-\mathrm{Al}$ supercooled liquid. Thus, $\mathrm{Fe}-\mathrm{Nd}-\mathrm{Al}$ supercooled liquid is considered to have a high degree of dense random packing density in the supercooled liquid by satisfying the factors: (1) multicomponent elements, (2) significant difference in atomic size ratios, and (3) large and negative heats of mixing. These factors are frequently utilized for the development of bulk metallic glasses with high glass-forming ability.

Figure 6 shows the hysteresis $J-H$ loops of the bulk $\mathrm{Fe}_{50} \mathrm{Nd}_{35} \mathrm{Al}_{15}$ amorphous alloy rods with a diameter of 1 and $1.5 \mathrm{~mm}$ prepared by the copper mold casting method, together with the melt-spun amorphous ribbon for comparison. The remanence $\left(B_{\mathrm{r}}\right)$, magnetization under a field of $1432 \mathrm{kA} / \mathrm{m}\left(J_{1432}\right)$ and intrinsic coercive field $\left({ }_{\mathrm{i}} H_{\mathrm{c}}\right)$ of the bulk $\mathrm{Fe}_{50} \mathrm{Nd}_{35} \mathrm{Al}_{15}$ amorphous alloy are measured to be $0.094 \mathrm{~T}, 0.414 \mathrm{~T}$ and $15 \mathrm{kA} / \mathrm{m}$, respectively, for the $1 \mathrm{~mm}$ sample, and $0.117 \mathrm{~T}, 0.36 \mathrm{~T}$ and $50 \mathrm{kA} / \mathrm{m}$, respectively, for the $1.5 \mathrm{~mm}$ sample. The appearance of the semi-hard magnetic properties for the amorphous $\mathrm{Fe}_{50} \mathrm{Nd}_{35} \mathrm{Al}_{15}$ alloy

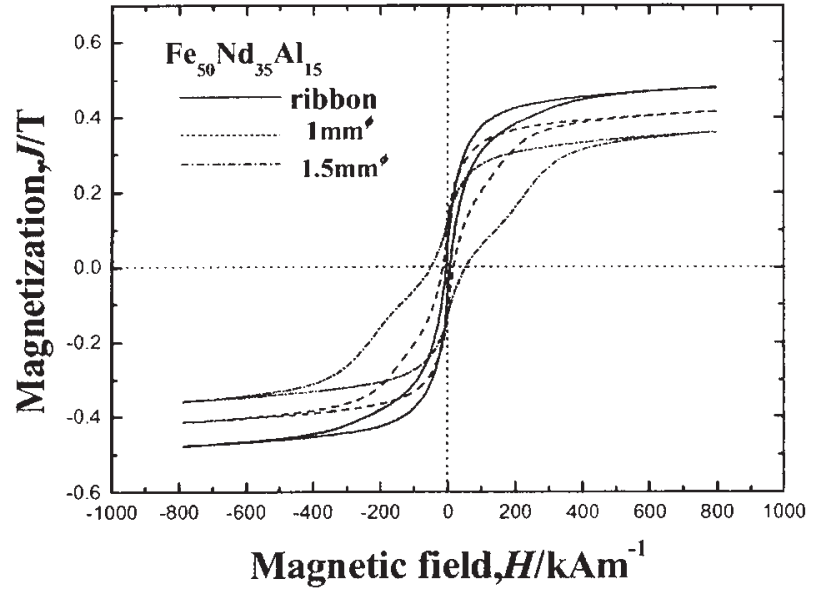

Fig. 6 Hysteresis $J-H$ loops of the melt-spun amorphous ribbon and the as-cast $\mathrm{Fe}_{50} \mathrm{Nd}_{35} \mathrm{Al}_{15}$ cylinders with diameters of 1 and $1.5 \mathrm{~mm}$.

rod with a diameter of $1.5 \mathrm{~mm}$ has been interpreted to result from the random magnetic anisotropy ${ }^{30,31)}$ caused by the development of short-range $\mathrm{Nd}-\mathrm{Fe}$ and $\mathrm{Nd}-\mathrm{Fe}-\mathrm{Al}$ atomic pairs. On the contrary, the hysteresis curve of the ribbon specimen shows soft magnetic properties, as can be seen in Fig. 6. Thus, the $\mathrm{Fe}_{50} \mathrm{Nd}_{35} \mathrm{Al}_{15}$ alloy has a sample size dependence of the magnetic properties. In other words, the soft to hard magnetic transition between ribbons and bulk specimens is observed in the $\mathrm{Fe}_{50} \mathrm{Nd}_{35} \mathrm{Al}_{15}$ alloy. This phenomenon has also been reported in the bulk amorphous Nd-rich $\mathrm{Nd}-\mathrm{Fe}-\mathrm{Al}$ alloys. ${ }^{32)}$ the Therefore, it can be concluded that the soft to hard magnetic transition takes place not only in the Nd-rich $\mathrm{Nd}-\mathrm{Fe}-\mathrm{Al}$ bulk amorphous alloys but also in the Fe-rich $\mathrm{Fe}-\mathrm{Nd}-\mathrm{Al}$ bulk amorphous alloys. But the reason of it is not very clear yet and need further investigated, however, comparing to the previous research results about $\mathrm{Nd}-\mathrm{Fe}-\mathrm{Al}$ bulk amorphous alloy, the reason for exhibiting soft-hard transition presumably due to the different microstructure caused by different cooling rates.

\section{Summary}

With the aim of preparing an Fe-rich $\mathrm{Fe}-\mathrm{Nd}-\mathrm{Al}$ bulk amorphous alloy with hard magnetic properties at room temperature, the structure, thermal stability and magnetic properties were investigated for cast $\mathrm{Fe}_{50} \mathrm{Nd}_{50-x} \mathrm{Al}_{x}(x=5$, $10,15,20)$ alloys. The results obtained in the present study are summarized as follows:

(1) The XRD and OM results show that the cast $\mathrm{Fe}_{50^{-}}$ $\mathrm{Nd}_{35} \mathrm{Al}_{15}$ alloy rods with diameters of 1 and $1.5 \mathrm{~mm}$ consist of an amorphous phase.

(2) The bulk $\mathrm{Fe}_{50} \mathrm{Nd}_{35} \mathrm{Al}_{15}$ amorphous alloy with a diameter of $1.5 \mathrm{~mm}$ shows the reduced crystallization temperature $\left(T_{\mathrm{x}} / T_{\mathrm{m}}\right)$ of 0.88 , and $\Delta T_{\mathrm{m}}\left(=T_{\mathrm{m}}-T_{\mathrm{x}}\right)$ of $106 \mathrm{~K}$. The large amorphous-forming ability is due to the extremely high $T_{\mathrm{x}} / T_{\mathrm{m}}$ and small $\Delta T_{\mathrm{m}}$.

(3) The bulk $\mathrm{Fe}_{50} \mathrm{Nd}_{35} \mathrm{Al}_{15}$ amorphous alloy with a diameter of $1.5 \mathrm{~mm}$ exhibits semi-hard magnetic properties of $0.117 \mathrm{~T}$ for remanence and $50 \mathrm{kA} / \mathrm{m}$ for intrinsic coercive field at room temperature.

(4) It is found that soft to hard magnetic transition between 
ribbon and bulk specimens occurs not only in Nd-rich $\mathrm{Nd}-\mathrm{Fe}-\mathrm{Al}$ alloys but also in $\mathrm{Fe}-\mathrm{rich} \mathrm{Fe}-\mathrm{Nd}-\mathrm{Al}$ alloys.

\section{REFERENCES}

1) A. Inoue, K. Kita, T. Zhang and T. Masumoto: Mater. Trans., JIM 30 (1989) 722-725.

2) A. Inoue, T. Zhang and T. Masumoto: Mater. Trans., JIM 31 (1990) 425-428.

3) A. Inoue, A. Kato, T. Zhang, S. G. Kim and T. Masumoto: Mater. Trans., JIM 32 (1991) 609-616.

4) A. Inoue, T. Nakamura, N. Nishiyama and T. Masumoto: Mater. Trans., JIM 33 (1992) 937-945.

5) A. Inoue, T. Zhang, N. Nishiyama, K. Ohba and T. Masumoto: Mater. Trans., JIM 34 (1993) 1234-1237.

6) A. Inoue, T. Zhang and T. Masumoto: Mater. Trans., JIM 36 (1995) 391-398.

7) A. Inoue, T. Zhang, N. Nishiyama, K. Ohba and T. Masumoto: Mater. Sci. Eng. A 179-180 (1994) 210-214.

8) A. Peker and W. L. Johnson: Appl. Phys. Lett. 63 (1993) 2342-2344.

9) A. Inoue, N. Nishiyama and T. Matusda: Mater. Trans., JIM 37 (1996) $181-184$.

10) A. Inoue and J. S. Gook: Mater. Trans., JIM 36 (1995) 1282-1285.

11) A. Inoue and J. S. Gook: Mater. Trans., JIM 36 (1995) 1180-1183.

12) A. Inoue, Y. Shinohara and J. S. Gook: Mater. Trans., JIM 36 (1995) 1427-1433.

13) A. Inoue and J. S. Gook: Mater. Trans., JIM 37 (1996) 32-38.

14) A. Inoue, T. Zhang, W. Zhang and A. Takeuchi: Mater. Trans., JIM 37 (1996) 99-108.

15) A. Inoue, T. Zhang, A. Takeuchi and W. Zhang: Mater. Trans., JIM 37 (1996) 636-640.
16) J. Ding, Y. Li and X. Z. Wang: J. Phys. D 32 (1999) 713-716.

17) M. J. Kramer, O. A. S. Connor, K. W. Dennis, R. W. McCallum, L. H. Lewis, L. D. Tung and N. P. Duong: IEEE Trans. Magn. 37 (2001) 2497-2499.

18) N. Lupu, R. Delaplane, R. L. McGreevy and H. Chiriac: Appl. Phys. A 74 (2002) S680-S682.

19) Z. G. Sun, W. Loser, J. Eckert, K. H. Muller and L. Schultz: J. Magn. Mater 261 (2003) 122-130.

20) H. Z. Kong, Y. Li and J. Ding: J. Magn. Mater. 217 (2000) 65-73.

21) A. Takeuchi and A. Inoue: Mater. Trans. 43 (2002) 1985-1991.

22) N. Chau, N. H. Luong, C. X. Huu, N. X. Phuc and N. H. Dan: J. Magn. Mater. 242-245 (2002) 1314-1316.

23) G. J. Fan, W. Lose, S. Roth, J. Eckert and L. J. Schultz: J. Mater. Res. 15 (2000) 1556-1563.

24) G. Kumar, J. Eckert, S. Roth, W. Loser, L. Schultz and S. Ram: Acta, Mater. 51 (2003) 229-238.

25) B. C. Wei, Y. Zhang, Y. X. Zhuang, D. Q. Zhao, M. X. Pan, W. H. Wang and W. R. Hu: J. Appl. Phys. 89 (2001) 3529-3531.

26) K. Q. Qiu, H. F. Zhang, A. M. Wang, B. Z. Ding and Z. Q. Hu: Acta, Mater. 50 (2002) 3567-3578.

27) Z. G. Sun, W. Loser, J. Eckert, K. H. Muller and L. Schultz: J. Appl. Phys. 91 (2002) 9267-9271.

28) H. Chiriac and N. Lupu: Mater. Sci. Eng. A 304-306 (2001) 727-730.

29) N. Chau, N. H. Luong, C. X. Huu, N. T. Thep and H. D. Anh: J. Magn. Mater. 262 (2003) 441-444.

30) K. Nagayama, H. Ino, N. Saito, Y. Nakagawa, E. Kita and K. Siratori: J. Phys. Soc. Jpn. 59 (1990) 2483-2495.

31) J. Filippi, B. Dieny and B. Barbara: Solid State Commun. 53 (1985) 523-527.

32) A. Takeuchi and A. Inoue: Mater. Sci. Eng. A 375-77 (2004) 11401144 . 